\title{
Insulin Sensitivity and Vascular Disease in Maturity-onset Diabetics
}

\author{
A. E. STOCKS,* M.B., B.S., M.R.A.C.P.; F. I. R. MARTIN, $\dagger$ M.D., F.R.A.C.P.
}

British Medical fournal, 1969, 4, 397-399

Cummary : In 27 maturity-onset diabetics of more than D 10 years' duration there was a significant tendency for both atherosclerosis and microangiopathy to be associated with a reduction in the acute hypoglycaemic effect of intravenous beef insulin. This finding is identical to that in a group of 51 insulin-dependent diabetics previously reported.

It is suggested that insulin insensitivity probably precedes the appearance of vascular disease in diabetes and may be implicated in its production.

\section{Introduction}

A significant association between the presence of clinical vascular disease and a reduced hypoglycaemic effect of intravenous insulin has been reported previously in a group of longterm insulin-dependent diabetics (Martin and Stocks, 1968). We report here a similar association in maturity-onset nonketotic diabetics not receiving insulin.

\section{Material and Methods}

Twenty-seven diabetics of maturity-onset type were studied; the only criteria for selection were a duration of diabetes mellitus exceeding 10 years, without any evidence of ketosis, the co-operation of the patients, and the availability of adequate diabetic records for at least five years. Their ages ranged from 45 to 78 years, and duration of diabetes from 10 to 25 years. Only one patient exceeded her ideal body weight by more than $20 \%$.

Eight patients had required short courses of insulin therapy in the past, but none had received insulin for at least five years previous to the study. Two patients were controlled by diet alone; the remainder were taking oral hypoglycaemic drugs.

All attended as outpatients, having fasted overnight and omitted their morning hypoglycaemic therapy. Blood samples for plasma glucose and insulin were taken via an indwelling needle in the resting state, and $5,10,15,20,30,45$, and 60 minutes after the intravenous injection of 0.1 units $/ \mathrm{kg}$. of glucagon-free beef insulin.

Blood glucose was determined by AutoAnalyzer, and plasma insulin levels by the dextran-coated charcoal radioimmunoassay (Pearson, Fullerton, Martin, and Melick, 1968 ; Stocks, Pearson, and Odom, 1968). Insulin sensitivity was expressed as the glucose assimilation index, an expression of the maximum percentage fall of blood glucose per minute after insulin (Norgaard and Thaysen, 1929). Reasons for the choice of this method of expression have been discussed elsewhere (Martin and Stocks, 1967). The half-time of disappearance of plasma insulin was determined by plotting the values, in micro-units per ml., semilogarithmically, and extrapolating from the line of best fit.

The vascular status was assessed as by Martin and Stocks (1968) by full clinical examination performed at the time of the insulin sensitivity test. The presence of atherosclerotic

\footnotetext{
- Physician to Diabetic Clinic, Princess Alexandra Hospital, Brisbane, Queensland, Australia.

t Endocrinologist, Royal Melbourne Hospital, Parkville, Victoria, Australia.
}

disease was indicated by a definite history of myocardial infarction, angina pectoris, stroke, intermittent claudication or gangrene from major arterial occlusion, by the presence of typical changes in the retinal vessels, and by the absence of peripheral pulses in the legs. Diabetic microangiopathy was characterized by the presence of typical retinal changes, persistent proteinuria in the absence of any symptomatic or microscopical evidence of urinary tract infection, and objective evidence of peripheral neuritis. Despite the lack of precision of any clinical estimate of vascular disease, an attempt was made to grade the features of both atherosclerosis and microangiopathy in each patient as nil, mild, moderate, or severe.

In 20 patients the fasting plasma cholesterol was determined by an AutoAnalyzer technique, and in 17 the fasting triglycerides were measured by the method of Lofland (1964). Statistical methods used were those of Snedecor (1956).

\section{Results}

The glucose assimilation index varied from 1.0 to 3.6 (mean 2.18) (Table I), and, as can be seen in Fig. 1, this fell between the mean value of 1.44 obtained in insulin-dependent juvenileonset diabetics and that of 2.75 found in normal subjects.

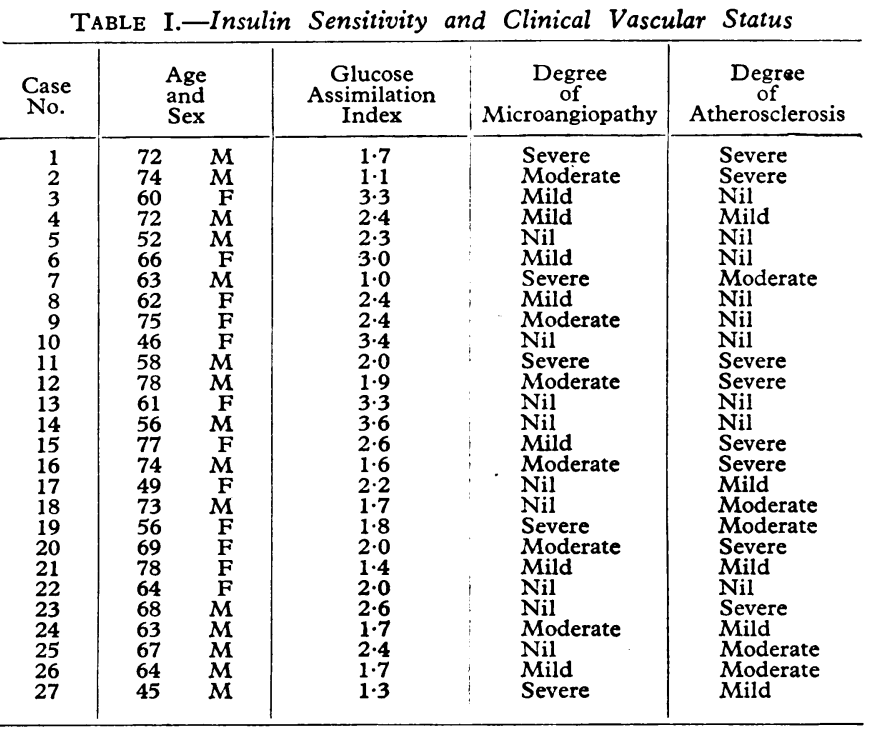

There was no relation between insulin sensitivity and the age, sex, or body build of the patients, nor with the duration of diabetes or the type of therapy required. In particular, a history of previous insulin therapy had no discernible effect on insulin sensitivity, and no patient had detectable anti-insulin antibodies as determined by increased binding of ${ }^{125} \mathrm{I}$-insulin in the charcoal radioimmunoassay (Fullerton and Martin, 1968). The glucose assimilation index was also unrelated to the fasting blood sugar level measured at the beginning of the test.

Eighteen patients $(67 \%)$ had clinical evidence of atherosclerosis, which was judged severe in eight cases. Increasing atherosclerosis correlated well with increasing age $(r=0.47$, $P<0.005$ ), but was not related to the duration of diabetes. 
There was a very significant tendency for those patients with demonstrable atherosclerosis to be relatively insensitive to insulin, and vice versa ( $\chi^{2}$ for linear trend $=54.6, P<0.0001$ ) as seen in Table II and Fig. 2.

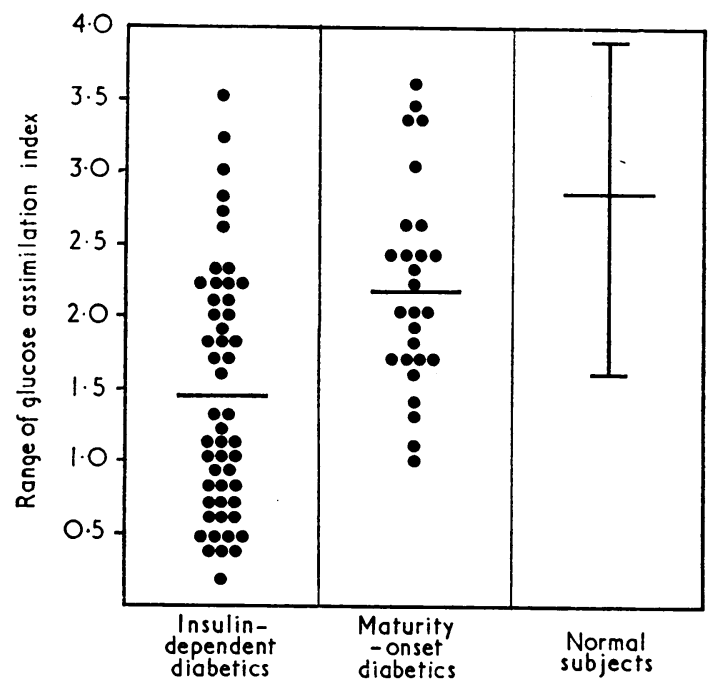

FrG. 1.-Range of glucose assimilation index in insulindependent diabetics, maturity-onset diabetics, and normal subjects.

TABLE II

\begin{tabular}{|c|c|c|}
\hline \multirow{2}{*}{ Rarge of G.A.I. } & \multicolumn{2}{|c|}{ Atherosclerosis } \\
\hline & Nil & Present \\
\hline $\begin{array}{c}1 \cdot 0-1 \cdot 9 \\
2 \cdot 0-2 \cdot 9 \\
3 \cdot 0 \text { and over }\end{array}$ & $\begin{array}{l}0 \\
4 \\
5\end{array}$ & $\begin{array}{r}11 \\
7 \\
0\end{array}$ \\
\hline
\end{tabular}

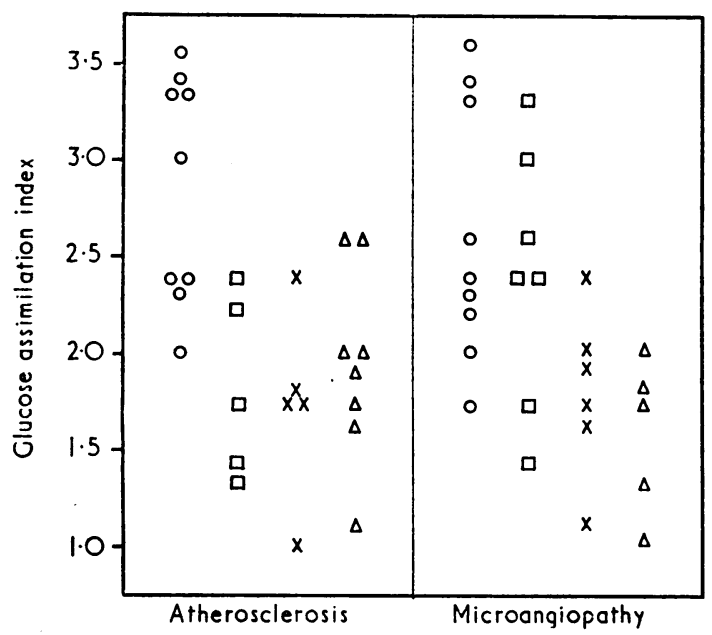

FIG. 2.-Relation of vascular status to insulin sensitivity. Vascular disease key: $O=N$ il, $\square=$ Mild, $x=$ Moderate, $\triangle=$ Severe.

Eighteen patients (67\%) had clinical microangiopathy, which was considered to be severe or moderately severe in 11 cases. There was no correlation between microangiopathy and either the age of the patients or the duration of diabetes. Nevertheless, as seen in Table III and Fig. 2, insulin insensitivity

TABLE III

\begin{tabular}{c|c|c}
\hline \multirow{2}{*}{ Range of G.A.I. } & \multicolumn{2}{|c}{ Microangiopathy } \\
\cline { 2 - 3 } & Minimal & Established \\
\hline $1 \cdot 0-1.9$ & 3 & 8 \\
$2 \cdot 0-2.9$ & 8 & 3 \\
3.0 and over & 5 & 0 \\
\hline
\end{tabular}

was again significantly more common in those patients with established microangiopathy $\left(\chi^{2}\right.$ for linear trend $=8 \cdot 23$, $\mathbf{P}<0.005)$. Patients with atherosclerosis tended also to have evidence of microangiopathy $(P<0.01)$.

An attempt was made to assess the success of control of the diabetes retrospectively from clinical records as follows: good control = no glycosuria, all blood sugars $<180 \mathrm{mg}$. $/ 100 \mathrm{ml}$.; fair control=usually no glycosuria, blood sugars $<250 \mathrm{mg}$./ $100 \mathrm{ml}$. ; poor control = frequent glycosuria, blood sugars sometimes $>250 \mathrm{mg} . / 100 \mathrm{ml}$. In this way the control of 11 cases was classified as good, 11 as fair, and 5 as poor. Insulin insensitivity and vascular disease, particularly atherosclerosis, occurred more often in those patients who were poorly controlled.

Plasma cholesterol (range 118-329 mg./100 ml.) and triglycerides (range $71-190 \mathrm{mg} . / 100 \mathrm{ml}$.) were both normal in the great majority of cases, and were not related to either the glucose assimilation index or vascular disease.

The half-time of disappearance of insulin from the circulation was determined in 22 patients and varied from $4 \cdot 0$ to $10 \cdot 0$ minutes (mean $6.4 \pm 1.7$ minutes). There was no apparent relation between the half-time of disappearance of insulin and the age of the patients nor the duration of diabetes. Also there was no relation with the glucose assimilation index, or with the presence of atherosclerosis or microangiopathy.

\section{Discussion}

In this series 23 of 27 maturity-onset diabetics had a glucose assimilation index after intravenous insulin within the normal range, with a mean value of $2 \cdot 18$. This is lower than that of normal patients who have a mean of $2 \cdot 75$, but much higher than the mean glucose assimilation index of 1.44 found in 51 insulin-dependent diabetics (Martin and Stocks, 1968). As the glucose assimilation index is reproducible it is probably a valid criterion to use in the definition of carbohydrate metabolism in diabetes. The degree of hypoglycaemic effectiveness of intravenous insulin was found to be inversely proportional to the severity of clinical atherosclerosis and microangiopathy. We believe that, despite the lack of precision possible in quantitating vascular disease, the degree of correlation between insulin insensitivity and vascular disease is such as to suggest a real relationship which is very similar to that reported previously for long-term insulin-dependent diabetics (Martin and Stocks, 1968). The difference in insulin sensitivity between the insulindependent and maturity-onset diabetic groups may be related to the presence of insulin antibodies in the former causing a pronounced reduction in the acute hypoglycaemic effect of insulin. Several of the patients in the present series had received short courses of insulin many years previously, but none had detectable insulin antibodies. A similar spectrum of insulin sensitivity has been found in patients studied many years after receiving insulin therapy for schizophrenia, who also had no detectable insulin antibodies at the time of study (Martin and Alford, unpublished).

A history of good control of diabetes in these maturity-onset diabetics was found to be associated with both a high glucose assimilation index and a relative absence of vascular disease. This association was not found in our earlier study of juvenileonset diabetics, where fluctuations of blood sugar are such as to make the degree of control almost impossible to assess. The present findings lend support to the contention of Joslin (1946) and his followers (Wilson, Root, and Marble, 1951) that good control of diabetes is importani in the prevention of vascular disease.

Whether insensitivity to insulin precedes the vascular changes and in some way predisposes to them or whether vascular disease decreases the biological effectiveness of insulin remains unknown. Butterfield, Garratt, and Whichelow (1963) have shown that there is a decreased loss of ${ }^{131}$ I-labelled insulin from the circulation of diabetics compared with non-diabetic 
subjects, but they did not attempt to relate this change to the presence of vascular disease. In the present series there was no tendency for immunoreactive insulin to disappear from the circulation more slowly in those patients with obvious vascular disease, though the mean time of disappearance was slower than that in non-diabetic subjects, a finding which supports the previous report by Stimmler (1967). This would suggest that there was no barrier to the passage of insulin out of the circulation owing to vascular disease, but it cannot be regarded as being conclusive because of the importance of hepatic removal of insulin in determining the acute disappearance from the circulation (Kaplan and Madison, 1959). On the other hand, there is some evidence that insulin insensitivity may precede vascular change, as 12 out of 25 diabetic patients studied within a month of diagnosis showed evidence of insulin insensitivity with a glucose assimilation index of less than 1.5 .

The possibility that there is a circulating insulin antagonist, either in plasma or at a tissue level, has been debated since the division of diabetics into so-called insulin-sensitive and insensitive types by Himsworth (1936). The recent finding that a peptide fragment of growth hormone has an inhibitory effect on insulin-like activity at the glyceraldehyde dehydrogenase step (Bornstein, Krahl, Marshall, Gould, and Armstrong, 1968) is of great interest. It seems possible that an excess of such an inhibitor could provide an explanation of the early occurrence of insulin insensitivity in recently diagnosed diabetics. So far, however, this activity has been demonstrated only in extracted pituitary tissue, and has not been convincingly shown to occur in plasma or to be related to insulin insensitivity.

A possible sequence of events suggested by the above findings is that insensitivity to insulin present from the outset of diabetes may allow hyperglycaemia (and thus poor control) and cause glucose metabolism to be directed along non-insulin-dependent pathways, giving rise among other things to an increased production of glucosamine and mucopolysaccharides (Spiro, 1963). These could be important in accelerating the development of diabetic vascular disease.
A prospective study to determine the time relationship between insulin insensitivity and vascular disease is in progress. If this supports the above hypothesis the insulin sensitivity test could be used early in the course of diabetes to help define a group of patients at greater risk of developing atherosclerosis and microangiopathy.

We are grateful to Dr. W. G. Oakley, Physician in Charge, Diabetic Department, King's College Hospital, London, for permission to study patients under his care. The help of Dr. I. McDonald, Department of Biochemistry, Guy's Hospital, and Dr. C. W. Baird and Miss Margaret Pearson, of the Department of Biochemistry, Royal Melbourne Hospital, are acknowledged.

This study was supported by a Sheppard M. Lowe Scholarship of the University of Melbourne (A. E. S.) and by the National Health and Medical Research Council of Australia.

\section{REFERENCES}

Bornstein, J., Krahl, M. E., Marshall, L. B., Gould, M. K., and Armstrong, J. (1968). Biochimica et Biophysica Acta, 156, 31 . Butterfield, W. J. H., Garratt, C. J., and Whichelow, M. J. (1963). Clinical Science, 24, 331.

Fullerton, M., and Martin, F. I. R. (1968). Medical fournal of Australia, 2, 744 .

Himsworth, H. (1936). Lancet, 1, 127.

Joslin, E. P. (1946). New England fournal of Medicine, 234, 442.

Kaplan, N., and Madison, L. L. (1959). Clinical Research, 7, 145.

Lofland, H. B., jun. (1964). Analytical Biochemistry, 9, 393.

Martin, F. I. R., and Stocks, A. E. (1967). Australasian Annals of Medicine, 16, 289.

Martin, F. I. R., and Stocks, A. E. (1968). British Medical Journal, 2, 81 .

Norgaard, A., and Thaysen, T. E. (1929). Acta Medica Scandinavica, 72, 492.

Pearson, M. J., Fullerton, M. J., Martin, F. I. R., and Melick, R. (1968). Proceedings of the Australian Association of Clinical Biochemists, 1, 315 .

Snedecor, G. W. (1956). Statistical Methods, Applied to Experiments in Agriculture and Biology, 5th ed. Ames, Iowa, Iowa State College Press.

Spiro, R. G. (1963). New England fournal of Medicine, 269, 566.

Stimmler, L. (1967). Diabetes, 16, 652

Stocks, A. E., Pearson, M. J., and Odom, N. J. (1968). Guy's Hospital Reports, 117, 275 .

Wilson, J. L., Root, H. F., and Marble, A. (1951). American fournal of the Medical Sciences, 221, 479.

\title{
Mechanism of Action of $\beta$-Adrenergic Receptor Blocking Agents in Angina Pectoris : Comparison of Action of Propranolol with Dexpropranolol and Practolol
}

\author{
A. G. WILSON,* M.B., B.S., M.R.C.P. ; O. G. BROOKE, $\dagger$ M.B., B.S., M.R.C.P. ; H. J. LLOYD, $†$ M.B., B.S., M.R.C.P. \\ B. F. ROBINSON, $\ddagger$ M.D., M.R.C.P.
}

British Medical fournal, 1969, 4, 399-401

\begin{abstract}
Summary : The effect on exercise tolerance of racemic $\checkmark$ propranolol has been assessed in eight angina pectoris patients and compared with that of dexpropranolol (the dextro isomer of propranolol), practolol (I.C.I. 50172), and saline. Dexpropranolol has the same local anaesthetic action as propranolol with negligible $\beta$-adrenergic receptor blocking activity, while practolol is a cardio-selective $\beta$-adrenergic blocking agent which does not have local anaesthetic activity.
\end{abstract}

Saline and dexpropranolol had no significant effect on exercise time; racemic propranolol and practolol

* Medical Registrar.

† Senior House Officer.

$¥$ Senior Lecturer in Medicine.

Medical Unit, St. George's Hospital, London S.W.1. improved exercise tolerance in six subjects, the response to the two drugs being very similar in individual patients. It was concluded that the beneficial effect of propranolol in angina pectoris results from its action as a $\beta$-adrenergic receptor blocking agent and is not due to its local anaesthetic, or quinidine-like, activity.

\section{Introduction}

The effect of $\beta$-adrenergic receptor blocking agents in improving exercise tolerance in patients with angina pectoris has been confirmed by a number of controlled trials. Pronethalol, the first such agent to be used clinically, was shown to be effective in a multicentre double-blind trial (Alleyne et al., 1963), and similar results were subsequently reported with propranolol 